\title{
Effect of propranolol on thyroid homeostasis of healthy volunteers
}

\author{
M.R. Wilkins, J.A. Franklyn ${ }^{1}$, K.L. Woods* and M.J. Kendall \\ Department of Therapeutics and Clinical Pharmacology and 'Department of Medicine, Queen Elizabeth Hospital. \\ Edgbaston, Birmingham B15 2TH, UK.
}

\begin{abstract}
Summary: The effect of propranolol on thyroid status was investigated by administering the drug in 2 therapeutic doses $(80 \mathrm{mg}$ b.d. and $120 \mathrm{mg}$ b.d.) to 8 healthy volunteers and serially measuring total and free thyroid hormones and their major binding protein. Mean free $T_{3}$ fell by $1.2 \mathrm{pmol} / 1(P<0.05)$ whilst mean free $T_{4}$ and mean $r T_{3}$ rose by $3.3 \mathrm{pmol} / 1(P<0.01)$ and $0.16 \mathrm{nmol} / \mathrm{l}(P<0.01)$ respectively. Mean thyroxine binding globulin (TBG) fell by $1.2 \mathrm{mg} / \mathrm{l}(P<0.001)$. Despite the change in free hormone levels there was no significant change in TSH. For the first time the effect of propranolol on circulating thyroid hormones and binding proteins in healthy subjects is apparent within one study. The biological significance of the change in free hormone levels is discussed.
\end{abstract}

\section{Introduction}

Beta-adrenoceptor blocking drugs (beta-blockers) have established a place in the treatment of thyrotoxicosis and it has been argued that their therapeutic effect, at least in part, may be mediated by a direct effect on thyroid hormone concentrations (Saunders et al., 1978). Changes in total thyroid hormone levels have been reported in patients receiving beta-blockers for hypertension and angina (Kristensen \& Weeke, 1977; Cooper et al., 1982). There is then the suggestion that these drugs may directly alter thyroid status. In view of the large number of euthyroid patients taking beta-blocking agents, we felt it was important to investigate this possibility in detail. The biologically active component of circulating thyroxine $\left(\mathrm{T}_{4}\right)$ and triiodothyronine $\left(\mathrm{T}_{3}\right)$ is thought to be the free (unbound) fraction. Free $\mathrm{T}_{4}$ and free $\mathrm{T}_{3}$ account for only $0.03 \%$ and $0.3 \%$, respectively, of total levels (Ekins, 1979). This study was designed to clarify the effects of propranolol on thyroid status by administering the drug in 2 therapeutic doses to healthy volunteers and monitoring not only total $T_{4}$ and $T_{3}$, reverse $T_{3},\left(r T_{3}\right)$, TSH and thyroxine binding globulin (TBG) but also free $T_{4}$ and free $T_{3}$.

Correspondence: M.R. Wilkins, M.R.C.P., Dept. of Therapeutics, Queen Elizabeth Hospital, Edgbaston, Birmingham BI5 2TH

*Present address: Dept. Pharmacology and Therapeutics, Leicester Royal Infirmary, P.O. Box 65, Leicester LE2 7LX. Accepted: 12 June 1984

\section{Methods}

Eight euthyroid male volunteers aged 20 to 23 y were studied. Each had a normal clinical examination, full blood count and biochemical profile. Baseline thyroid function was assessed on 2 venous samples taken a week apart. Propranolol, $80 \mathrm{mg}$ twice daily, was started on day 0 and continued until day 14 . On day 15 , after the morning blood sample, the dose was increased to $120 \mathrm{mg}$ twice daily for a further week. Propranolol was stopped on day 21. Blood was sampled for thyroid function tests on days $1,2,3,7,14$, $15,21,22,23$ and 28 and compliance was checked by measuring plasma levels of propranolol on days 3,7 and 15.

Total $\mathrm{T}_{3}, \mathrm{~T}_{4}$ and $\mathrm{rT}_{3}$ were measured by in-house radioimmunoassay (Black et al., 1975; Evans et al., 1977). Free $T_{4}$, free $T_{3}$ and TSH were measured using Amerlex kit methods and TBG by immunoelectrophoresis (Laurell, 1966). The possibility of an in vitro effect of propranolol on the free hormone assays was examined by assaying a sample of normal serum containing different concentrations of propranolol (range 0 to $1000 \mathrm{ng} / \mathrm{ml}$ ) for free $T_{4}$ and $T_{3}$.

The increments and decrements from the mean for each individual for each day were analysed by Student's $t$ test and Wilcoxon rank sum test. There was close agreement between the two statistical approaches. For consistency, as standard errors are given, the values of significance quoted are those calculated by Student's $t$ test. 


\section{Results}

There was a non-significant rise in total $\mathrm{T}_{4}$ during the treatment period and a return to baseline on stopping the beta-blocker. Total $T_{3}$ levels remained stable throughout the study (Figure 1). Despite changes in total and free thyroid hormone levels (Figure 2) there was no significant change in basal TSH concentration during the study period.

Mean free $\mathrm{T}_{4}$ rose during the first week from a basal level of $19.8( \pm$ s.e.m. 0.9$)$ to $22.7( \pm 1.0) \mathrm{pmol} / \mathrm{l}$ on day $7(P<0.02)$. With some fluctuation in absolute values, it remained elevated for the rest of the treatment period, returning to baseline on stopping the drug (Figure 2).

The mean basal free $T_{3}$ was $6.4( \pm 0.3) \mathrm{pmol} / \mathrm{l}$. There was no significant change during the period of low dose propranolol but there was a signficant fall to $5.2( \pm 0.2) \mathrm{pmol} / \mathrm{l}(P<0.05)$ on $120 \mathrm{mg}$ b.d. and a sharp rise towards the basal value on stopping the drug (Figure 2).

Reverse $\mathrm{T}_{3}$ rose during the first week from a baseline level of $0.44( \pm 0.02)$ to $0.57( \pm 0.03) \mathrm{nmol} / 1$ $(P<0.01)$. It remained elevated throughout the treatment period, falling to basal levels after day 21 .

TBG fell gradually from $9.4( \pm 0.3)$ to a nadir of 8.2 $( \pm 0.4) \mathrm{mg} / \mathrm{l}(P<0.001)$ on day 22 and then showed a trend of gradual recovery during the post-treatment week (Figure 3 ). The change in $\mathrm{T}_{4} / \mathrm{TBG}$ ratio showed a very close correlation with the response of measured free $\mathrm{T}_{4}(\mathrm{r}=0.9 ; P<0.001)$ (Figure 4).
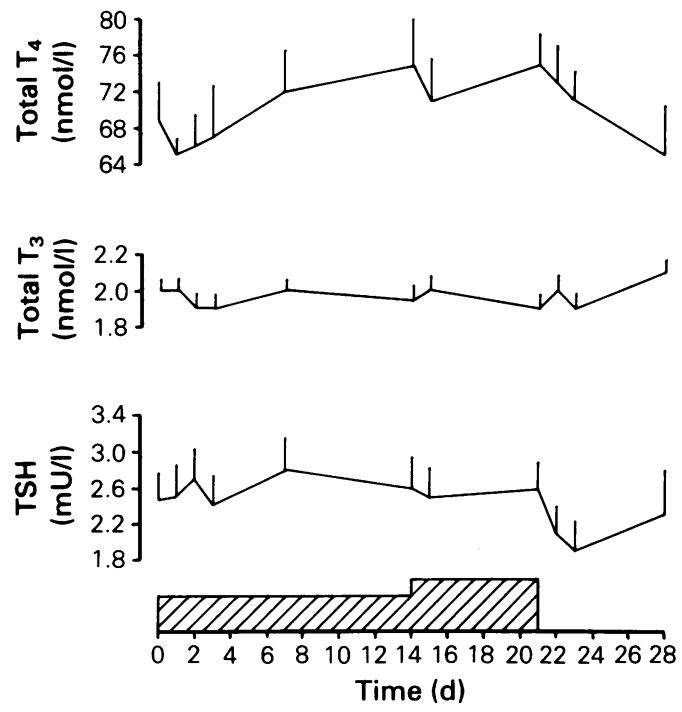

Figure 1 Total $\mathrm{T}_{4}$ and $\mathrm{T}_{3}$ and TSH levels during treatment with propranolol (hatched area) and in the follow-up week.
The addition of propranolol to serum in vitro inf increasing concentrations produced a slight but non-气 significant rise in measured free $T_{4}$ and had no effect3 on measured free $T_{3}$.

\section{Discussion}

Previously reported changes in total thyroid hormone $\frac{\overline{\bar{F}}}{\mathrm{~s}}$ levels in euthyroid subjects receiving propranolol may be summarized thus: total $\mathrm{T}_{3}$ may fall whilst reverse ${ }^{\propto}$ $T_{3}$, and on higher doses, total $T_{4}$ may rise. Theses changes, however, have never previously been des- $\overrightarrow{0}$ cribed in one study (Cavalieri \& Rivers, 1981). Lotti $e t-$ al. (1977) and Faber et al. (1979) noted a fall in $T_{3}$ with $\bar{\omega}$ propranolol 40 to $120 \mathrm{mg} / \mathrm{d}$ and the latter group alsoo recorded a rise in reverse $T_{3}$, but neither group found aO change in total $\mathrm{T}_{4}$ levels. Kristensen \& Weeke (1977). and Cooper et al. (1982) reported raised total $\mathrm{T}_{4}$ levels. in patients receiving propranolol for essential hyper- $\overrightarrow{-}$ tension and angina pectoris respectively; five of the six ${ }_{\omega}^{\mathcal{N}}$ described by Cooper et al. (1982) also had raised levels $\Theta$ of $\mathrm{rT}_{3}$ but both groups of patients had normal total $\mathrm{T}_{3} \mathrm{O}$ levels. The changes in total hormone concentrations found in our study - the rise in $\mathrm{rT}_{3}$, the non-significant 3 rise in $\mathrm{T}_{4}$ and the stable $\mathrm{T}_{3}$ levels - are compatible with the observations of others.

Kristensen \& Weeke (1977) included measuremerofsso
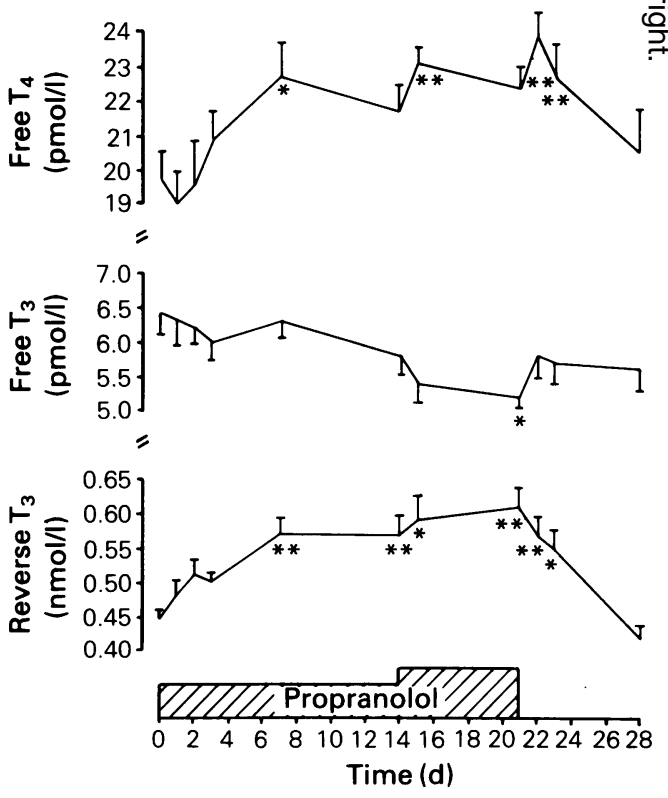

Figure 2 Response of free $T_{4}$ and $T_{3}$ and reverse $T_{3}$ during treatment with propranolol $(80 \mathrm{mg}$ b.d. and then $120 \mathrm{mg}$ b.d.) and in the follow-up week. Day 0 is the mean of two basal values for each volunteer. ${ }^{*} P<0.05$; ** $P<0.01$. 

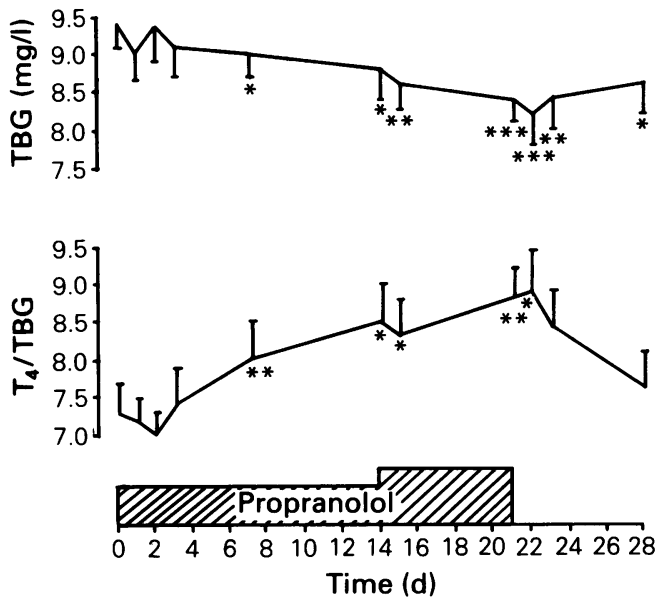

Figure 3 Response of TBG and change in $\mathrm{T}_{4} / \mathrm{TBG}$ ratio during treatment with propranolol $(80 \mathrm{mg}$ b.d. and then $120 \mathrm{mg}$ b.d.) and in the follow-up week. Day 0 is the mean of two basal values for each individual. ${ }^{*} P<0.05$; ${ }^{* *} P<0.01 ;{ }^{* * *} P<0.001$.

of free $T_{4}$ and free $T_{3}$ in their study of 15 patients starting propranolol for essential hypertension. Their results differ from ours in that they observed a rise in free $T_{4}$ but no change in free $T_{3}$. Their patients were taking other antihypertensive drugs and the authors base their report on 2 blood samples for each individual taken 30 days apart, two factors which may have reduced the sensitivity of their study.

In this report, changes in free thyroid hormones parallelled those described for total circulating hormones, and for the first time the effects of propranolol on thyroid hormones, total and free, and their major binding protein are apparent in one study. Most $T_{3}$ and $r T_{3}$ is produced by the monodeiodination of $T_{4}$ in peripheral tissues - liver and kidney - rather than in the thyroid (Chopra et al., 1978). The changes in free $T_{4}$, free $T_{3}$ and $\mathrm{rT}_{3}$ presented here provide strong supporting evidence for an inhibitory influence of

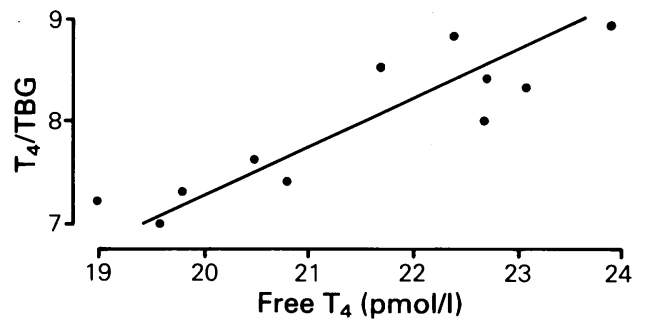

Figure 4 Correlation of estimated free $T_{4}\left(T_{4} / T B G\right.$ ratio) and measured free $T_{4}$ during the study period (on and off propranolol). $\mathrm{r}=0.9 ; P<0.001$. propranolol on $5^{\prime}$ monodeiodinase. This enzyme is responsible for the monodeiodination of $T_{4}$ to $T_{3}$ (Chopra et al., 1978) and $\mathrm{rT}_{3}$ to $\mathrm{T}_{2}$, hence $\mathrm{T}_{3}$ production falls and $\mathrm{rT}_{3}$ clearance is reduced if its activity is inhibited. The mechanism by which propranolol exerts this inhibitory effect is unclear. The property is not confined to propranolol but is shared by some other beta-blockers (Perrild et al., 1983). DL-propranolol, which has no known beta-blocking activity, has also been reported to decrease $T_{3}$ and increase $r T_{3}$ levels (Heyma et al., 1980).

The fall in TBG that occurs during propranolol therapy was first noted by Wilkinson et al. (1983). It occurs in euthyroid subjects and in thyrotoxic patients once rendered euthyroid. It cannot be attributed to changes in plasma volume as serum albumin levels remain unaffected. The very close correlation between the $T_{4} / T B G$ ratio (an estimate of free $T_{4}$ ) and the measured free hormone (Figure 4) suggests that the fall in TBG does not invalidate the use of the $T_{4} / \mathrm{TBG}$ ratio in patients taking propranolol. Furthermore, this close correlation affords independent evidence supporting the argument that the rise in free $T_{4}$ is genuine and not explained by an effect of propranolol on the free $T_{4}$ assay. In contrast, there was no correlation between the change in $T_{3} / T B G$ ratio and the response of free $\mathrm{T}_{3}$.

Interpretation of the biological significance of an $18 \%$ fall in free $\mathrm{T}_{3}$ and a concurrent $20 \%$ rise in free $\mathrm{T}_{4}$ is complicated by the lack of a definitive standard by which to assess thyroid status. In euthyroid subjects, serum levels of free $T_{4}$ and free $T_{3}$ remain remarkably constant with time (unpublished data). A fall of $1.2 \mathrm{pmol} / 1$ in free $\mathrm{T}_{3}$ and a rise of around $3.0 \mathrm{pmol} / 1 \mathrm{in}$ free $T_{4}$ in absolute terms in healthy volunteers is unphysiological. The net effect of these divergent responses on metabolism depends upon the relative potencies of free $T_{4}$ and free $T_{3}$. It has been estimated that $T_{4}$ is 2 to 4 times less potent in stimulating calorigenesis than $T_{3}$, and that $T_{4}$ has no catabolic activity (Perrild et al., 1983). Therefore the overall effect may be that there is a net fall in catabolic activity.

At present the two most sensitive indicators of 'adequacy' of circulating thyroid hormone levels are the serum TSH level and its response to thyrotrophin releasing hormone (TRH). In this study, there was no significant change in TSH levels. Cooper et al. (1982) included TRH stimulation in their series of patients on high-dose propranolol; they obtained normal or blunted, rather than exaggerated, TSH responses to TRH stimulation. Thus there is no evidence as yet to suggest that the pituitary appreciates treatment with propranolol as drug-induced hypothyroidism but the definitive test awaits the discovery of a sensitive assay of biological activity of thyroid hormones at the tissue level. 


\section{References}

BLACK, E.G., GRIFFITHS, R.S., FINUCANE, J. \& HOFFENBERG, R. (1975). Radioimmunoassay of $T_{3}$ and $T_{4}$ in serum and urine. In Thyroid Hormone Metabolism, Harland, W.A. and Orr, J.S. (eds), pp. 347-366, Academic Press: London.

CAVALIERI, R.R., \& PITT-RIVERS, R. (1981). The effects of drugs on the distribution and metabolism of thyroid hormones. Pharmacological Reviews, 33, 55.

CHOPRA, I.J., SOLOMON, D.H., CHOPRA, O., SING YUNG, W., FISHER, D.A. \& NAKAMURA, Y. (1978). Pathways of metabolism of thyroid hormones. Recent Progress in Hormone Research, 34, 521.

COOPER, D.S., DANIELS, G.H., LADERSON, P.W. \& RIDGWAY, E.C. (1982). Hyperthyroxaemia in patients treated with high-dose propranolol. American Journal of Medicine, 73, 867.

EKINS, R.P. (1979). Methods for the measurement of free thyroid hormones. In Free Thyroid Hormones (Proceedings of International Symposium, Venice, 1978). Ekins, R., Faglia, G., Pennisi, F. and Pinchera, A. (eds) pp.72-92. Excerpta Medica: Amsterdam.

EVANS, S.E., BURR, W.A. \& HOGAN, T.C. (1977). A reassessment of 8-anilino-1-naphthalene sulphonic acid as a thyroxine binding inhibitor in the radioimmunoassay of thyroxine. Annals of Clinical Biochemistry, 141, 330.

FABER, J., FRIIS, T. \& KIRKEGAARD, C. (1979). Serum T $4, T_{3}$ and reverse $T_{3}$ during treatment with propranolol in hyperthyroidism, $\mathrm{L}_{-} \mathrm{T}_{4}$ treated myxoedema and in normal man. Hormone and Metabolic Research, 11, 34.
HEYMA, P., LARKINS, R.G., HIGGINBOTHAM, L. \& NG. K.W. (1980). D-propranolol and DL-propranolol both decrease conversion of L-thyroxine to L-triiodothyronine. British Medical Journal, 281, 24.

KRISTENSEN, B.O. \& WEEKE, J. (1977). Propranolol induced increments in total and free serum thyroxine in patients with essential hypertension. Clinical Pharmacology and Therapeutics, 22, 864.

LAURELL, C.B. (1966). Quantitative estimation of proteins

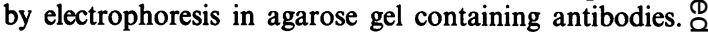
Analytical Biochemistry, 15, 45 .

LOTTI, G., DELITALA, G., DEVILla, L., AlAGNA, S. \& MASSALA, A. (1977). Reduction of plasma triiodothyron- $\vec{\circ}$ ine by propranolol. Clinical Endocrinology, 6, 405.

PERRILD, H., HANSEN, J., SKOVSTED, L. \& CHRISTENSEN, $\vec{\omega}$ L.K. (1983). Different effects of propranolol, alprenolol, sotalol, atenolol and metoprolol on serum $T_{3}$ and serum $\frac{0}{3}$ $\mathrm{rT}_{3}$ in hyperthyroidism. Clinical Endocrinology, 18, 139.

SAUNDERS, J., HALL, S.E.H., CROWTHER, A. \& SONKSEN, 9 P.H. (1978). The effect of propranolol on thyroid hormones and oxygen consumption in thyrotoxicosis. Clinical En- $\vec{G}$ docrinology, 9, 67.

WILKINSON, R., KAPADI, A.L., ASTON, E.M. \& RAMSDEN, D.B. (1983). The effect of B-blockade therapy on serum 음 thyroxine binding globulin (TBG) concentration. Acta Endocrinologica, 103, 352. 